Original Article

\title{
Tai Chi Exercise can Improve the Obstacle Negotiating Ability of People with Parkinson's Disease: A Preliminary Study
}

\author{
Hyeong-Dong Kim, PhD, $\mathrm{PT}^{1)^{*}}$, Hyun Dong Jae, $\mathrm{PhD}^{2)}$, J I Hoon Jeong PhD ${ }^{3)}$ \\ 1) Department of Physical Therapy, College of Health Science, Korea University: 1 Jeongneung \\ 3-dong, Sungbuk-gu, Seoul 136-703, Republic of Korea \\ 2) Department of Pharmacology, College of Pharmacy, Catholic University of Daegu, Republic of \\ Korea \\ 3) Department of Pharmacology, College of Medicine, Chung-Ang University, Republic of Korea
}

\begin{abstract}
Purpose] The purpose of this study was to examine the effects of Tai Chi (TC)-based exercise on dynamic postural control during obstacle negotiation by subjects with mild or moderate Parkinson's disease (PD). [Subjects] Twelve subjects (mean age, 65.3 \pm 6.1 years) diagnosed with idiopathic PD were enrolled for this study. [Methods] All the subjects were tested a week before and 12 weeks after the initiation of the TC exercise. In the test, they were instructed to negotiate an obstacle from the position of quiet stance at a normal speed. They were trained with TC exercise that emphasized multidirectional shift in weight bearing from bilateral to unilateral support, challenging the postural stability, three times per week for 12 weeks. Center of pressure (COP) trajectory variables before and after TC exercise were measured using two force plates. [Results] A comparison of the results between pre- and post-intervention showed a statistically significant improvement in anteroposterior and mediolateral displacement of COP. [Conclusion] Twelve weeks of TC exercise may be an effective and safe form of stand-alone behavioral intervention for improving the dynamic postural stability of patients with PD.

Key words: Obstacle negotiation, Parkinson's disease, Tai Chi exercise
\end{abstract}

(This article was submitted Dec. 16, 2013, and was accepted Jan. 8, 2014)

\section{INTRODUCTION}

Parkinson's disease (PD) is a chronic, progressive, neurodegenerative movement disorder of unknown etiology. It usually results from the continuous degeneration of dopanergic cells in the substantia nigra and depletion of dopamine in the corpus striatum ${ }^{1)}$. Parkinsonism is characterized by the gradual development of two or more of the major symptoms: bradykinesia (reduced speed of movement), resting tremor, rigidity, akinesia (poverty of movement), postural instability, and cognitive impairment as well as age related impairments, such as decreased muscle strength of the lower extremities ${ }^{2,3)}$. In general, all of these signs and symptoms can variously affect the ambulation of an individual.

Impairments in postural control and locomotion lead not only to declined function and quality of life, but an increased incidence of falls and hip fractures which are estimated in the USA to cost approximately US\$ 192 million annually ${ }^{4,5)}$. The risk of falls for people with PD is twice that of the general healthy population, and approximately

*Corresponding author. Hyeong-Dong Kim (E-mail: hdkimx0286@yahoo.com)

(C2014 The Society of Physical Therapy Science. Published by IPEC Inc. This is an open-access article distributed under the terms of the Creative Commons Attribution Non-Commercial No Derivatives (by-ncnd) License $<$ http://creativecommons.org/licenses/by-nc-nd/3.0/> .
$70 \%$ of people with PD fall during the course of the disease, often resulting in serious injuries and hospitalization ${ }^{6,7)}$. Approximately $27 \%$ of people with PD had new hip fractures 10 years after the first diagnosis ${ }^{8)}$, and approximately $3 \%$ of hospitalized people with PD become wheelchair dependent ${ }^{9)}$.

Impaired mobility like postural instability, which is a major cause of disability in patients with $\mathrm{PD}$, is less responsive to pharmacological and surgical therapies, even though some motor deficits, such as tremor, may be alleviated by medication ${ }^{10,11)}$. Thus, patients diagnosed with PD often turn to alternative approaches for alleviation of their symptoms making exercise and physical therapy an attractive option.

Exercise is often recommended for persons with PD, because regular physical activity has been shown to slow their decline in mobility and to prolong functional independence ${ }^{12,13)}$. The strength of the lower extremity muscles of PD patients and regular exercise are associated with their capacity to perform functional tasks, such as walking and sit-to-stand ${ }^{14-17)}$. Several intervention strategies including general exercise, high-intensity resistance training, and sensory cue training improve balance, strength, and freezing gait of people with $\mathrm{PD}^{18-21)}$. These previous studies examining the effectiveness of exercise training for patients with PD required a variety of equipment to perform, and safety monitoring was needed. Few studies have assessed 
alternative forms of exercise programs for PD patients that could delay their mobility disability and improve their motor function levels.

Only recently has growing attention been given by western science to Tai Chi (TC) exercise as an alternative intervention for the enhancement of human well-being that improves balance impairment and disability related to aging, and age-related diseases such as PD. TC exercise is a traditional Chinese martial art, and is a balance-based group of exercises with similarities to aerobic exercise. It involves a sequence of fluid, continuous, rhythmical, and graceful movements linked together in a continuous manner that flow smoothly from one movement to another. In the performance of TC, dynamic body weight shifting, rotations, and standing on a single leg, which require joint control, muscle coordination, and good balance performance, are repeatedly practiced ${ }^{22}$. All of these movements may be an effective means of addressing impairment in postural control during gait. Additionally, TC can be safely and inexpensively practiced at any time and in any place, because it does not require much space or any equipment ${ }^{23)}$.

TC is beneficial for improving flexibility, lower extremity strength, balance, physical function, and postural stability and reduces the risk of falls for elderly and frail individuals $^{24-29}$. Research on the effects of TC has provided promising results for patients with PD who have gait dysfunction and postural instability. Results from TC studies ${ }^{27}$, ${ }^{29-31)}$ suggest that the 50-ft speed walk, Timed Up-and-Go, Functional Reach Test, Unified Parkinson's Disease Rating Scale (UPDRS) motor subscale 3, Berg Balance Scale (BBS), Tandem Stance, and Six-Minute Walk and axial symptoms of PD, such as postural stability, were improved by TC.

Few studies have investigated the potential mechanisms by which TC may improve movement dysfunction and reduce falls among PD sufferers. Tripping during obstacle negotiation is one of the most commonly reported causes of falls among the elderly ${ }^{32,33)}$. Therefore, it is plausible that people with PD who have gait dysfunction and postural instability are also at a high risk of tripping over obstacles and falling. Given the known risk of falls for the elderly during obstacle negotiation and the fact that people with PD have difficulty in performing simultaneous motor or cognitive tasks, crossing obstacles, or attempting to walk in complex environmental settings ${ }^{34,35)}$, it is surprising the possible benefits of TC for those with PD during obstacle negotiation have received little attention.

Accordingly, the primary aim of this study was to examine the effects of TC-based exercise on dynamic postural control when people with mild or moderate PD negotiate an obstacle. Since the movements of TC contain many training components required for maintaining dynamic balance including shifting the body weight from a unilateral to a bilateral position, symmetric foot stepping, modifications in stance width, single leg support while standing upright, and controlled movements near the limits of stability, we hypothesized that TC exercise would be effective at improving the dynamic postural control while crossing an obstacle of persons with mild and moderate PD.
Table 1. Demographic and clinical characteristics of the study participants with PD at baseline.

\begin{tabular}{lc}
\hline Participant details & \\
\hline Sample size (number) & 12 \\
Age (year) & $65.3 \pm 6.1$ \\
Gender M/F (number) & $2 / 10$ \\
Height (cm) & $153.6 \pm 8.1$ \\
Weight (kg) & $54.1 \pm 6.8$ \\
MMSE score/30 (number) & $26.9 \pm 3.2$ \\
PD duration (months) & $56 \pm 13.3$ \\
HY scale/range (number) & $2.3 \pm 0.78 / 1-3$ \\
UPDRS motor subscale III/56 (number) & $20.6 \pm 9.7$ \\
\hline
\end{tabular}

Most values represent mean $\pm \mathrm{SD}$

PD, Parkinson's disease; M/F, male/female; MMSE, Mini Mental Status Examination; HY scale, Hoehn and Yahr scale; UPDRS, Unified Parkinson's Disease Rating Scale

\section{SUBJECTS AND METHODS}

Twelve subjects (2 men, 10 women; mean age, $65.3 \pm 6.1$ years; age range, $55-75)$ who had been diagnosed with idiopathic PD by a neurologist were enrolled for this study. Their mean Hoehn \& Yahr (H\&Y) disability ${ }^{36)}$ score was $2.3 \pm 0.78$ (it ranges from $1-3$, and higher scores indicate more severe disease), and their mean duration of PD was $56 \pm 13.3$ months (range, $45-80$ months). None of the participants had significant cognitive impairment (their Mini Mental State Examination (MMSE) ${ }^{37)}$ scores exceeded 25) and all the participants could walk independently at least $5 \mathrm{~m}$ without an assistive device. All the participants were being treated with anti-Parkinson's medication, and fully responded to their PD medications. They were examined at their peak "on" effect, which was approximately 1-1.5 hours after taking their anti-Parkinson's medications. None of the participants showed freezing gait over the course of the study.

Subjects were excluded if they had any serious medical problem; any history or evidence of neurological deficit, other than PD, which could have interfered with locomotion, such as previous stroke or neuromuscular disease; severe dementia determined by a MMSE score $<24$ (indicating some degree of cognitive impairment); inability to walk independently; inability to complete the TC exercise program due to debilitating conditions or vision impairment; previous training in any form of TC exercise or current participation in any instructor-led structured regular exercise program; or inability to understand the instructions. All subjects read and signed the informed consent forms approved by the University Institutional Review Board prior to the start of data collection. Baseline participant demographics are summarized in Table 1.

An experienced TC instructor taught the first eight movements of 24 simplified short forms of the Yang style $\mathrm{TC}^{38)}$, a standard and popular TC routine, to people with $\mathrm{PD}$ over the course of TC training. The TC interventions, which consisted of $10 \mathrm{~min}$ of warm-up exercises, $40 \mathrm{~min}$ of eight movements of TC, and $10 \mathrm{~min}$ of cool-down exercises, were 
done three times a week for 12 weeks. The TC protocol was specifically developed to emphasize components of movement typically limited in the elderly and more serious case of PD.

Warm-up exercise included slow and gentle flexibility exercises of the shoulders, neck, arms, knees, hips, and back, followed by a trunk stretching exercise that coordinated weight shift with trunk rotation and active arm swinging as well as isolated static TC movements. TC exercise consisted of a series of slow, gentle, relaxed, continuous, rhythmic, coordinated, and flowing movements of different body parts, which emphasized multidirectional weight shifting, trunk rotations, awareness of body alignment, multi-segmental (arms, legs, and trunk) coordination, and narrowing of lower extremity stance and multidirectional shift in weight bearing from bilateral to unilateral support, challenging the postural stability. Synchronized breathing aligned with TC movements was incorporated and integrated into the movement routine. The mastery of one-to-two forms through multiple repetitions was emphasized each week for the first 8 weeks. The complete form was practiced for the last 4 weeks, focusing on repetitions to improve balance and gait. Cool-down exercises included: smooth and progressive range of motion exercises of the ankles, knees, hips, and back as well as neck, and a meditation that incorporated diaphragmatic breathing exercise. The instructor explained and demonstrated how each form should be performed, and the participants followed the motions.

Evaluation of all participants was performed a week before and 12 weeks after the initiation of the exercise regimen. Two experienced physical therapists blinded to the TC intervention collected the data. During each assessment, participants were first evaluated for disease severity using the UPDRS motor subscale $3^{39)}$ and MMSE, and then completed an obstacle crossing task.

Two force platforms (AMTI, Newton, MA, USA) mounted flush with a walkway surface (5 $\mathrm{m}$ in length and $1.5 \mathrm{~m}$ in width) measured the ground reaction forces (GRFs) while the participants crossed the obstacle. Amplified force plate signals were sampled on-line at a rate of $1,000 \mathrm{~Hz}$ for $5 \mathrm{~s}$ (AMTI). GRFs collected from two force platforms were processed and the center of pressure (COP) data were analyzed using BioAnalysis v2.0 software (AMTI). The test conditions included the use of obstacles $(10 \mathrm{~cm}$ in height, $10 \mathrm{~cm}$ in depth and $140 \mathrm{~cm}$ in width) made of wood for obstacle clearance.

For each trial, participants stood quietly with their arms hanging at their sides in a self-selected foot position with each foot on a force plate in a relaxed posture. The two force platforms were placed adjacent to each other with narrow edges to measure the GRFs. Initial positioning of each participant's feet on the force platform was traced and the tracings were used before starting a new trial of obstacle crossing to reposition the foot on the force platform to increase the between-trial consistency. Participants were then instructed to cross an obstacle at a comfortable, normal speed with the right limb after receiving the auditory cue of a 'go' signal, and continued to walk a minimum of three steps. For each participant, two practice trials to familiarize
Table 2. COP measures of both feet at baseline and 12 weeks

\begin{tabular}{llr}
\hline Parameters & Time & \multicolumn{1}{c}{ TC } \\
\hline Swing limb & & \\
& Baseline & $9.87(3.56)$ \\
A-P displacement $(\mathrm{cm})^{*}$ & 12 weeks & $12.63(4.64)$ \\
& Baseline & $2.54(0.98)$ \\
M-L displacement $(\mathrm{cm})^{*}$ & 12 weeks & $3.46(1.23)$ \\
Stance limb & & \\
& Baseline & $11.13(2.76)$ \\
A-P displacement $(\mathrm{cm})^{*}$ & 12 weeks & $13.45(5.42)$ \\
& Baseline & $3.58(1.12)$ \\
M-L displacement $(\mathrm{cm})^{*}$ & 12 weeks & $4.83(2.3)$ \\
\hline
\end{tabular}

Values represent mean $\pm \mathrm{SD}$

TC, Tai Chi; COP, center of pressure; A-P, anteroposterior; M-L, mediolateral

*Significant difference $(\mathrm{p}<0.05)$ between pre- and post-intervention for both feet

themselves with the experimental procedure were followed by approximately five successful experimental trials. All participants were required to wear flat-soled shoes normally used for everyday walking or sports activities.

COP trajectory variables before and after TC exercise were compared using the paired t-test. Statistical significance was accepted for values of $p<0.05$. Force platform variables selected for analysis included anteroposterior (A$\mathrm{P}$ ) and mediolateral (M-L) displacement of the COP. A-P (or $\mathrm{M}-\mathrm{L}$ ) displacement of the COP was defined as the total distance (or difference) between the minimum and maximum A-P (or M-L) COP location for the length of time when either the left or right foot was in contact with the force platform. SPSS 14.0 KO (SPSS, Chicago, IL, USA) was used for all statistical analyses.

\section{RESULTS}

All participants followed their own protocol and completed the initial and post- assessments. No outliers were found in any of the COP measurements and data from all participants were used in the statistical analysis. After the TC intervention, all participants showed a clinically meaningful improvement in measured COP displacements (Table 2). In the comparison of pre- and post-intervention results, the PD participants showed statistically significant improvements in all the measured COP displacements $(p<0.05)$. Participants showed a $124 \%$ and $135 \%$ increase in A-P and M-L displacement of the COP, respectively, for both the swing and stance limbs. The mean values of the PD participants' outcome measures after the intervention are summarized in Table 2.

\section{DISCUSSION}

The development of cost-effective evidence-based interventions to decrease falls and fall-related injuries for persons with PD is needed. TC exercise is often recommended for managing the symptoms of PD. However, there have 
been very few investigations of biomechanical changes in postural control and gait after TC exercise in people with PD.

The current study investigated the effectiveness of TC exercise on the ability to step over an obstacle by people with PD. A 12-week, 3-times weekly TC intervention improved the COP measures, which represent muscle responses to maintain dynamic stability while stepping over an obstacle, for both limbs. The results confirmed our hypothesis that $\mathrm{TC}$ exercise would be effective at improving the dynamic postural control while crossing an obstacle of persons with mild to moderate PD.

The decreased COP displacement in both directions (A-P and M-L) shown by PD patients may be related to dysfunction in balance, akinesia, hypokinesia, or tremor/movement discontinuities associated with $\mathrm{PD}^{40)}$. In our present study, TC exercise led to improvements in A-P and M-L displacement of COP while stepping over an obstacle. Mean COP displacement in the A-P and M-L directions increased by $24 \%$ and $35 \%$, respectively, after TC exercise, as compared to pre-intervention. These results are consistent with the findings of a previous study ${ }^{41)}$, which demonstrated increased COP displacement in the A-P and M-L directions during gait initiation after $\mathrm{PD}$ patients had performed TC exercises. The improvements in COP measures were also similar to those reported previously for older adults without PD who practiced TC exercise ${ }^{25,42)}$. In these earlier studies, the elderly subjects showed improvements in COP trajectory variables during either gait initiation or obstacle crossing. In addition, Hass et al. ${ }^{43)}$ reported that individuals with PD who received 10 weeks of resistance training significantly increased the magnitude of COP displacement in the posterior direction when initiating gait. Furthermore, Rogers et al. ${ }^{44)}$ demonstrated that individuals with PD significantly increased the magnitude of COP displacement in the posterior and lateral directions when a startling acoustic stimulus was delivered prior to initiation of walking. In contrast, no significant improvement in selected gait initiation parameters was reported following 16 weeks of $60 \mathrm{~min}$ TC exercise for people with mild to moderate $\mathrm{PD}^{45)}$. This lack of improvement in outcome measures may have been due, in part, to heterogeneity of a wide spectrum of PD participants and the wide variability of TC exercise regimens ${ }^{45}$.

Control of the center of mass by manipulation of the movement of the COP in the A-P and M-L directions while stepping over an obstacle is an important consideration for dynamic postural stability ${ }^{46)}$. The posterior movement of the COP in the initial period of stepping is needed to generate forward momentum to initiate walking ${ }^{47)}$. Thus, greater posterior COP movement increases the moment arm by which the GRF can move the center of mass forward ${ }^{25)}$. Previous studies ${ }^{25,48,49)}$ have shown that a reduction in the magnitude of the backward COP displacement occurs with advancing age and disability when initiating gait. Deterioration in centrally mediated anticipatory postural adjustments is believed to be responsible for the reduction in the backward COP displacement ${ }^{47)}$.

In this study, 12 subjects with PD were able to improve A-P displacement of the COP to an average of $13.04 \mathrm{~cm}$, which is close to the value previously reported for elderly individuals with $\mathrm{PD}$ who practiced $\mathrm{TC}^{41)}$. This increase in the magnitude of the displacement of the A-P COP observed for the PD subjects may be attributable to restoration of centrally mediated anticipatory postural adjustments during obstacle avoidance. During initiation of walking there is an inhibition of the tonic soleus, which is active during quiet stance, followed by the onset of tibialis anterior activity in both the swing and stance limbs ${ }^{50,51)}$. This combination is responsible for the backward movement of the $\mathrm{COP}^{50-52)}$. PD patients are known to generate insufficient dorsiflexion torque due to inappropriate and/or inefficient tibialis anterior activation during the initiation of gait ${ }^{53,54)}$. PD patients are also unable to turn off previously activated muscles, such as the soleus and gastrocnemius, due to an inability to gate or scale the postural and voluntary components of the motor task ${ }^{55}$. These contribute to a limitation in the backward displacement of the COP.

While stepping over an obstacle, the COP created by the swing limb hip abductors moves laterally toward the swing limb and generates stance-side momentum; that is, momentum toward the stance limb ${ }^{56}$. Thus, the coordinated action of the ankle and hip muscles tend to propel the center of mass forward and toward the intended stance limb. Previous studies ${ }^{48,57,58)}$ have reported that the COP displacement towards the swing limb shown by individuals with PD during gait initiation is significantly smaller than that of healthy age-matched older adults. This reduced ability to modulate M-L COP displacement shown by people with PD during gait initiation might be due to alterations in the proximal musculature strength ${ }^{59)}$, particularly the muscles of the hip ${ }^{16)}$.

The post-intervention average displacement of the M-L COP for the PD subjects was $4.15 \mathrm{~cm}$, a $34 \%$ increase compared to pre-intervention. This finding indicates that TC exercise improves M-L COP displacement. The improvement in the M-L COP displacement may be attributable to the coordinated action of the hip abductor and adductor muscles after TC exercise ${ }^{60)}$. Older adults with disability and those transitioning to frailty have reduced M-L COP displacements, and people with PD who have greater M-L and A-P COP displacements, and people who have a greater weight shift between the two limbs have a longer step during gait initiation ${ }^{48)}$. Furthermore, children with autistic disorder who exhibit less age-related development and postural instability also have reduced M-L COP displacement during gait initiation, compared to age-matched normally developing children ${ }^{61}$. Given that many studies have consistently reported a reduced displacement of the M-L COP in individuals with postural instability when initiating gait, the significantly increased displacement of the M-L COP seen in the present study is indicative of the increased dynamic postural stability of the PD participants who practiced TC exercise.

This study had a number of limitations. The sample size of the patients was small and no control group was included. It was difficult to determine the exact contribution of the treatment to the measured changes without a control group; therefore, the present improvements in postural con- 
trol cannot be conclusively attributed to the TC exercise. In addition, the TC exercise was performed for a 12-week period, which is relatively short in terms of providing the full benefit of the exercise to people with PD. Moreover, no follow-up data were collected. It was not possible to determine whether the improvements were temporary or permanent. Furthermore, the change in the exact timing and spatial events of gait parameters after the intervention were not analyzed because only two force plates were used in the current study. Synchronized analysis of kinematic and kinetic data would provide better insight into the effects of TC exercise on PD patients than the separate analysis of kinetic data. Further studies will be needed to assess the dynamic stability of people with PD using this technique.

In conclusion, $\mathrm{TC}$ exercise increased the magnitude of the COP displacement in the A-P and M-L directions, thereby improving the mechanism by which momentum is generated in the A-P and M-L directions in the initiation of gait and the maintenance of balance and lateral stability. The present findings support the view that short-term TC exercise may be an effective and safe form of stand-alone behavioral intervention that can be easily conducted outdoors or indoors on an individual or group basis to improve the postural stability of some individuals with mild to moderately severe PD. However, a more definitive conclusion regarding the efficacy of TC exercise for people with $\mathrm{PD}$ cannot be made until more evidence is available. A well designed randomized controlled trial using a larger patient population and follow-up is required to enhance our present findings regarding the effectiveness of TC exercise for people with $\mathrm{PD}$.

\section{ACKNOWLEDGEMENT}

This research was supported by Basic Science Research Program through the National Research Foundation of Korea (NRF) funded by the Ministry of Education, Science and Technology (NRF-2012R1A1A2044235).

\section{REFERENCES}

1) Morris ME, Huxham F, McGinley J, et al.: The biomechanics and moto control of gait in Parkinson disease. Clin Biomech (Bristol, Avon), 2001, 16: 459-470. [Medline] [CrossRef]

2) Morris ME: Locomotor training in people with Parkinson disease. Phys Ther, 2006, 86: 1426-1435. [Medline] [CrossRef]

3) Canning CG, Sherrington C, Lord SR, et al.: Exercise therapy for prevention of falls in people with Parkinson's disease: a protocol for a randomised controlled trial and economic evaluation. BMC Neurol, 2009, 9: 4. [Medline] [CrossRef]

4) Melton LJ 3rd, Leibson CL, Achenbach SJ, et al.: Fracture risk after the diagnosis of Parkinson's disease: influence of concomitant dementia. Mov Disord, 2006, 21: 1361-1367. [Medline] [CrossRef]

5) Bacon WE: Secular trends in hip fracture occurrence and survival: age and sex differences. J Aging Health, 1996, 8: 538-553. [Medline] [CrossRef]

6) Hely MA, Reid WG, Adena MA, et al.: The Sydney multicenter study of Parkinson's disease: the inevitability of dementia at 20 years. Mov Disord, 2008, 23: 837-844. [Medline] [CrossRef]

7) Bloem BR, Hausdorff JM, Visser JE, et al.: Falls and freezing of gait in Parkinson's disease: a review of two interconnected, episodic phenomena. Mov Disord, 2004, 19: 871-884. [Medline] [CrossRef]

8) Johnell O, Melton LJ 3rd, Atkinson EJ, et al.: Fracture risk in patients with parkinsonism: a population-based study in Olmsted County, Minnesota Age Ageing, 1992, 21: 32-38. [Medline] [CrossRef]
9) Koller WC, Glatt S, Vetere-Overfield B, et al : Falls and Parkinson's disease. Clin Neuropharmacol, 1989, 12: 98-105. [Medline] [CrossRef]

10) Nirenberg MJ, Fahn S: The role of levodopa and catechol-O-methyltransferase inhibitors. In: Schapira AHV, Olanow CW, eds. Principles of treatment in Parkinson's disease. Philadelphia: Butterworth-Heinemann Elsevier, 2005.

11) Schapira AH, Olanow CW: The medical management of Parkinson's disease. In: Schapira AHV, Olanow CW, eds. Principles of treatment in Parkinson's disease. Philadelphia: Butterworth-Heinemann Elsevier, 2005.

12) Dibble LE, Addison O, Papa E: The effects of exercise on balance in persons with Parkinson's disease: a systematic review across the disability spectrum. J Neurol Phys Ther, 2009, 33: 14-26. [Medline] [CrossRef]

13) Lugassy M, Gracies JM: Physical therapy in Parkinson's disease. In: Schapira AHV, Olanow CW, eds. Principles of treatment in Parkinson's disease. Philadelphia: Butterworth-Heinemann Elsevier, 2005.

14) Canning CG, Ada L, Johnson JJ, et al.: Walking capacity in mild to moderate Parkinson's disease. Arch Phys Med Rehabil, 2006, 87: 371-375. [Medline] [CrossRef]

15) Nallegowda M, Singh U, Handa G, et al.: Role of sensory input and muscle strength in maintenance of balance, gait, and posture in Parkinson's disease: a pilot study. Am J Phys Med Rehabil, 2004, 83: 898-908. [Medline] [CrossRef]

16) Inkster LM, Eng JJ, MacIntyre DL, et al.: Leg muscle strength is reduced in Parkinson's disease and relates to the ability to rise from a chair. Mov Disord, 2003, 18: 157-162. [Medline] [CrossRef]

17) Pääsuke $M$, Ereline J, Gapeyeva $H$, et al.: Leg-extension strength and chair-rise performance in elderly women with Parkinson's disease. J Aging Phys Act, 2004, 12: 511-524. [Medline]

18) Ashburn A, Fazakarley L, Ballinger C, et al.: A randomised controlled trial of a home based exercise programme to reduce the risk of falling among people with Parkinson's disease. J Neurol Neurosurg Psychiatry, 2007, 78: 678-684. [Medline] [CrossRef]

19) Nieuwboer A, Kwakkel G, Rochester L, et al.: Cueing training in the home improves gait-related mobility in Parkinson's disease: the RESCUE trial. J Neurol Neurosurg Psychiatry, 2007, 78: 134-140. [Medline] [CrossRef]

20) Hirsch MA, Toole T, Maitland CG, et al.: The effects of balance training and high-intensity resistance training on persons with idiopathic Parkinson's disease. Arch Phys Med Rehabil, 2003, 84: 1109-1117. [Medline] [CrossRef]

21) Dibble LE, Hale TF, Marcus RL, et al.: High-intensity resistance training amplifies muscle hypertrophy and functional gains in persons with Parkinson's disease. Mov Disord, 2006, 21: 1444-1452. [Medline] [CrossRef]

22) Lan C, Lai JS, Chen SY: Tai Chi Chuan: an ancient wisdom on exercise and health promotion. Sports Med, 2002, 32: 217-224. [Medline] [CrossRef]

23) Hong Y, Li JX, Robinson PD: Balance control, flexibility, and cardiorespiratory fitness among older Tai Chi practitioners. Br J Sports Med, 2000, 34 29-34. [Medline] [CrossRef]

24) Wu G: Evaluation of the effectiveness of Tai Chi for improving balance and preventing falls in the older population - a review. J Am Geriatr Soc, 2002, 50: 746-754. [Medline] [CrossRef]

25) Hass CJ, Gregor RJ, Waddell DE, et al.: The influence of Tai Chi training on the center of pressure trajectory during gait initiation in older adults. Arch Phys Med Rehabil, 2004, 85: 1593-1598. [Medline] [CrossRef]

26) Wolf SL, Barnhart HX, Kutner NG, et al.: Reducing frailty and falls in older persons: an investigation of Tai $\mathrm{Chi}$ and computerized balance training. Atlanta FICSIT Group. Frailty and Injuries: Cooperative Studies of Intervention Techniques. J Am Geriatr Soc, 1996, 44: 489-497. [Medline]

27) Li F, Harmer P, Fisher KJ, et al.: Tai Chi and fall reductions in older adults: a randomized controlled trial. J Gerontol A Biol Sci Med Sci, 2005, 60: 187-194. [Medline] [CrossRef]

28) Voukelatos A, Cumming RG, Lord SR, et al.: A randomized, controlled trial of tai chi for the prevention of falls: the Central Sydney tai chi trial. J Am Geriatr Soc, 2007, 55: 1185-1191. [Medline] [CrossRef]

29) Li F, Harmer P, Fisher K, et al.: Tai Chi-based exercise for older adults with Parkinson's disease: a pilot-program evaluation. J Aging Phys Act, 2007, 15: 139-151. [Medline]

30) Klein PJ, Rivers L: Taiji for individuals with Parkinson disease and their support partners: a program evaluation. J Neurol Phys Ther, 2006, 30: 22-27. [Medline] [CrossRef]

31) Hackney ME, Earhart GM: Tai Chi improves balance and mobility in people with Parkinson disease. Gait Posture, 2008, 28: 456-460. [Medline] [CrossRef]

32) Tinetti ME, Speechley M: Prevention of falls among the elderly. N Engl J Med, 1989, 320: 1055-1059. [Medline]

33) Campbell AJ, Borrie MJ, Spears GF, et al.: Circumstances and consequences of falls experienced by a community population 70 years and over 
during a prospective study. Age Ageing, 1990, 19: 136-141. [Medline] [CrossRef]

34) Bond JM, Morris M: Goal-directed secondary motor tasks: their effects on gait in subjects with Parkinson disease. Arch Phys Med Rehabil, 2000, 81 110-116. [Medline]

35) Morris ME, Iansek R, Matyas TA, et al.: Stride length regulation in Parkinson's disease. Normalization strategies and underlying mechanisms. Brain, 1996, 119: 551-568. [Medline] [CrossRef]

36) Hoehn MM, Yahr MD: Parkinsonism: onset, progression and mortality Neurology, 1967, 17: 427-442. [Medline] [CrossRef]

37) Folstein MF, Folstein SE, McHugh PR: "Mini-mental state". A practica method for grading the cognitive state of patients for the clinician. J Psychiatr Res, 1975, 12: 189-198. [Medline] [CrossRef]

38) Wang C, Collet JP, Lau J: The effect of Tai Chi on health outcomes in patients with chronic conditions: a systematic review. Arch Intern Med 2004, 164: 493-501. [Medline] [CrossRef]

39) Movement Disorder Society Task Force on Rating Scales for Parkinson' Disease: The Unified Parkinson's disease rating scale (UPDRS): status and recommendations. Mov Disord, 2003, 18: 738-750. [Medline] [CrossRef]

40) Hass CJ, Waddell DE, Wolf SL, et al.: Gait initiation in older adults with postural instability. Clin Biomech (Bristol, Avon), 2008, 23: 743-753. [Medline] [CrossRef]

41) Kim HD, Kim TY, Jae HD, et al.: The Effects of Tai Chi based exercise on dynamic postural control of Parkinson's disease patients while initiating gait. J Phys Ther Sci, 2011, 23: 265-269. [CrossRef]

42) Kim HD: Effects of Tai Chi exercise on the center of pressure trace during obstacle crossing in older adults who are at a risk of falling. J Phys Ther Sci, 2009, 21: 49-54. [CrossRef]

43) Hass CJ, Buckley TA, Pitsikoulis C, et al.: Progressive resistance training improves gait initiation in individuals with Parkinson's disease. Gait Posture, 2012, 35: 669-673. [Medline] [CrossRef]

44) Rogers MW, Kennedy R, Palmer S, et al.: Postural preparation prior to stepping in patients with Parkinson's disease. J Neurophysiol, 2011, 106 915-924. [Medline] [CrossRef]

45) Amano S, Nocera JR, Vallabhajosula S, et al.: The effect of Tai Chi exercise on gait initiation and gait performance in persons with Parkinson's disease. Parkinsonism Relat Disord, 2013, 19: 955-960. [Medline] [CrossRef]

46) Winter D: Biomechanics and Motor Control of Human Movement, 3rd ed Hoboken: John Wiley \& Sons, 2005.

47) Polcyn AF, Lipsitz LA, Kerrigan DC, et al.: Age-related changes in the initiation of gait: degradation of central mechanisms for momentum generation. Arch Phys Med Rehabil, 1998, 79: 1582-1589. [Medline] [CrossRef]
48) Martin M, Shinberg M, Kuchibhatla M, et al.: Gait initiation in community-dwelling adults with Parkinson disease: comparison with older and younger adults without the disease. Phys Ther, 2002, 82: 566-577. [Medline]

49) Patchay S, Gahéry Y, Serratrice G: Early postural adjustments associated with gait initiation and age-related walking difficulties. Mov Disord, 2002, 17: 317-326. [Medline] [CrossRef]

50) Breniere Y, Do MC: When and how does steady state gait movement induced from upright posture begin? J Biomech, 1986, 19: 1035-1040. [Medline] [CrossRef]

51) Brunt D, Lafferty MJ, Mckeon A, et al.: Invariant characteristics of gait initiation. Am J Phys Med Rehabil, 1991, 70: 206-212. [Medline] [CrossRef]

52) Crenna P, Frigo C: A motor programme for the initiation of forward-oriented movements in humans. J Physiol, 1991, 437: 635-653. [Medline]

53) Halliday SE, Winter DA, Frank JS, et al.: The initiation of gait in young, elderly, and Parkinson's disease subjects. Gait Posture, 1998, 8: 8-14. [Medline] [CrossRef]

54) Gantchev N, Viallet F, Aurenty R, et al.: Impairment of posturo-kinetic co-ordination during initiation of forward oriented stepping movements in parkinsonian patients. Electroencephalogr Clin Neurophysiol, 1996, 101: 110-120. [Medline] [CrossRef]

55) Frank JS, Horak FB, Nutt J: Centrally initiated postural adjustments in parkinsonian patients on and off levodopa. J Neurophysiol, 2000, 84 2440-2448. [Medline]

56) Rogers MW, Pai YC: Dynamic transitions in stance support accompanying leg flexion movements in man. Exp Brain Res, 1990, 81: 398-402. [Medline] [CrossRef]

57) McIlroy WE, Maki BE: The control of lateral stability during rapid stepping reactions evoked by antero-posterior perturbation: does anticipatory control play a role? Gait Posture, 1999, 9: 190-198. [Medline] [CrossRef]

58) Hahn ME, Chou LS: Can motion of individual body segments identify dynamic instability in the elderly? Clin Biomech (Bristol, Avon), 2003, 18: 737-744. [Medline] [CrossRef]

59) Lawrence DG, Kuypers HG: The functional organization of the motor system in the monkey. I. The effects of bilateral pyramidal lesions. Brain, 1968, 91: 1-14. [Medline] [CrossRef]

60) Winter DA, Patla AE, Ishac M, et al.: Motor mechanisms of balance during quiet standing. J Electromyogr Kinesiol, 2003, 13: 49-56. [Medline] [CrossRef]

61) Fournier KA, Kimberg CI, Radonovich KJ, et al.: Decreased static and dynamic postural control in children with autism spectrum disorders. Gait Posture, 2010, 32: 6-9. [Medline] [CrossRef] 